\title{
Os (des)caminhos de Clio em terras norte-americanas: episódios de uma história da história nos Estados Unidos
}

Arthur Lima de Avila*

Klein, Kerwin Lee. From history to theory. Berkeley: University of California Press, 2011.

Como escrever uma história da história nos Estados Unidos? Como dar conta das inúmeras e conturbadas mudanças epistemológicas, disciplinares e linguísticas ocorridas na historiografia daquele país? Como vinculá-las ao mundo extra-acadêmico? From history to theory, mais recente obra de Kerwin Lee Klein, professor da Universidade da Califórnia, Berkeley, busca dar conta dessas questôes. Autor de um magistral livro sobre a imaginação histórica estadunidense nos séculos XIX e XX, Frontiers of historical imagination (Berkeley, 1997), o historiador agora se volta, segundo suas próprias palavras, para uma "história episódica da história e teoria” (p. 5) nos Estados Unidos da última centúria. Nesse sentido, From history to theory é menos uma monografia do que uma coleção de ensaios que transitam por temas diversos, do declínio da palavra "historiografia" no discurso histórico norte-americano à ascensão da direita cristã no país, todos tendo um norte comum: traçar a genealogia de momentos discursivos importantes nos âmbitos acadêmicos e públicos estadunidenses. Em outras palavras, Klein pratica algo próximo à história conceitual alemã, mas sem possuir as mesmas ambições filosóficas da Begriffsgeschichte, tratando de historicizar certas palavras-chave, vinculando-as a tradiçóes narrativas e práticas linguísticas mais amplas. Trata-se, portanto, de um livro sobre as instáveis, cambiantes e problemáticas relaçóes entre termos diversos, dos quais "história" e "teoria" são os principais, em vários contextos dos Estados Unidos do século XX, mas, especialmente, os das suas duas ou três últimas décadas - anos das notórias "guerras teóricas" em torno da virada linguística, da nova história cultural e do famigerado "pós-modernismo".

Para Klein (p. 12), dois momentos foram cruciais para as mudanças ocorridas no discurso histórico estadunidense daquele período: a busca quase obsessiva, mas extremamente ilusória, por um status científico para a disciplina, com suas inúmeras justificaçóes filosóficas, e a descolonização dos continentes africano e asiático, que forçou os historiadores norte-americanos a lidar com diferenças culturais de maneira muito mais profunda do que antes. É sob esse pano de fundo que Klein constrói sua narrativa, como ele mesmo a chama (p. 5), buscando, contudo, não repetir aquelas histórias da história tradicionalmente progressistas e whiggish, que enredavam o desenvolvimento da historiografia como uma marcha constante 
em direção a estágios mais científicos e, por isso, melhores do que os anteriores. Não há aqui aquela ingenuidade que estipula aos "pós-modernos", por exemplo, a "destruição" dos pilares da historiografia "científica", tão comum a certas análises, ou, de outra maneira, a louvação acrítica de "novas" histórias que, com todos os seus "radicalismos" e "inovaçôes", seriam necessariamente melhores do que as anteriores. O plot é deveras mais complicado do que um simples enredo de ascendência ou decadência.

Isso fica claro na análise que Klein faz da ascensão e queda dos conceitos de "historiografia" e "filosofia da história" no discurso histórico norte-americano, bastante reveladoras acerca da memória disciplinar que se constituiu naquele país. No primeiro caso, nos anos que se seguiram à profissionalização da história, o termo "historiografia” possuía um significado ambíguo e era justamente essa falta de claridade que lhe dava crédito no mercado conceitual dos historiadores. "Historiografia” podia significar a "escrita da história" propriamente dita, o "estudo crítico da escrita da história", como defendido por nomes como Carl Becker e Charles Beard, e, finalmente, um corpus textual sobre algum tema específico (p. 19). Mais do que isso, o conceito podia combinar tanto uma reflexão filosófica sobre a prática histórica quanto uma narrativa da evolução do discurso histórico, o que o tornava essencial para aqueles que, como o pioneiro Frederick Jackson Turner, imaginavam a disciplina como algo mais do que a simples coleta de fatos e sua exposição "científica" numa narrativa “objetiva”. Dessa maneira, "historiografia" harmonizava os âmbitos teóricos e práticos da história, não os separando em formas estanques, como passaria a ocorrer a partir das décadas de 1950 e 1960. A partir dessas décadas, a burocratização e a superespecialização profissional, já analisadas por nomes como Ian Tyrrell (The great historical Jeremiad. The History Teacher, p. 371-393, May 2000) e Peter Novick (That noble dream. Cambridge, 1988), levaram a uma separação entre a reflexão teórica sobre a história e suas práticas disciplinares. Tal ruptura resultou no abandono dos cursos de "historiografia" oferecidos país afora e numa cada vez mais disseminada aversão à teoria, que se tornaria característica entre os historiadores norte-americanos da segunda metade do século XX. Além disso, para os dois lados do espectro político disciplinar, "historiografia" significava algo condenável ou realmente perigoso: para os conservadores, servia como porta de entrada para ataques teóricos à "história real"; para os radicais, ela funcionava como uma reafirmação do cânone e da preservação do establishment profissional. Não conseguindo convencer ninguém, "historiografia", entendida principalmente como uma reflexão crítica sobre a disciplina, se tornou um termo virtualmente desacreditado nos Estados Unidos, em que pesem esforços recentes de autores como Eileen Ka-May Cheng (Historiography: a field in search of a historian. History and Theory, p. 278-289, May 2013), Ian Tyrrell (Historians in public. Chicago, 2005), Ellen Fitzpatrick (History's memory. Cambridge, 2002), além do próprio Klein, em reabilitar a palavra. 
Ao mesmo tempo que o termo "historiografia" caía em desgraça entre os historiadores, "filosofia da história" emergia como um conceito importante. Aqui, as preocupaçóes de Klein com práticas linguísticas mais amplas entram em cena, com a hábil construção dos argumentos extradisciplinares que levaram à popularização do termo em terras estadunidenses. De acordo com ele (p. 45), "filosofia da história” encontrou eco especialmente entre dois grupos: aqueles acadêmicos vinculados à política e ao governo, interessados em encontrar um sentido metafísico mais amplo para o conflito entre "liberdade" (capitalismo) e "totalitarismo" (comunismo), e aqueles filósofos dispostos a perscrutar a tão propalada cientificidade da disciplina histórica e a encontrar uma linguagem verdadeiramente compatível com ela. Em ambos os casos, entretanto, os filósofos falharam não só em convencer seus próprios colegas da legitimidade de suas colocações, com os grandes departamentos de filosofia norte-americanos virtualmente ignorando "filosofia da história" enquanto uma disciplina passível de investimentos, como em alcançar os historiadores. Um exemplo de tal fracasso é o amplo debate da filosofia analítica envolvendo positivistas lógicos, como Carl Hempel e os defensores da covering law theory, e aqueles que rejeitavam tais argumentos, ainda que nos termos propostos pelos primeiros. Como demonstra Klein (p. 51-53), apenas um fraco eco de tais discussões alcançou os dedicados servidores de Clio. O pano de fundo de tal surdez, por assim dizer, é o mesmo que levou à decadência do conceito "historiografia": a pro- nunciada e cada vez mais agressiva rejeição dos historiadores em empreender grandes debates teóricos, entendidos como irrelevantes para aquilo que os historiadores (supostamente) faziam realmente: ir aos arquivos e, como dizem os norte-americanos, get the story straight.

Ainda assim, a despeito da opinião dos "historiadores reais" sobre elas, as discussóes continuaram. $\mathrm{O}$ engessado cientificismo professado pelos defensores da covering law theory, e não atacado de frente por seus opositores, levou a uma consequência que, a partir dos anos 1960, teria efeitos duradouros nos Estados Unidos: a reavaliação da história como uma arte, a ars historica, cujo lócus mais adequado de análise seria a crítica literária e não a filosofia analítica. Tal reação, melhor exemplificada nos trabalhos de Hayden White, especialmente no artigo "The burden of history" (1966) e no posterior livro clássico Metahistory (1973), significou uma virada em direção à estética para o julgamento crítico dos textos historiográficos e abriu o caminho para a linguistic turn das décadas de 1970 e 1980 (p. 56). Com tal mudança, pregou-se um dos últimos pregos no caixão da "filosofia da história", substituída pelo termo "teoria”, mais "neutro" e sem tantas conotações metafísicas — simbolizado na fundação daquele que, até os dias de hoje, é o principal journal sobre teoria e, apesar dos pesares, filosofia da história em língua inglesa, History and Theory, em 1966.

Isso leva à pergunta sobre o que, afinal de contas, foi a tal "virada linguística", ocorrida no esteio das transformaçóes linguísticas e disciplinares descritas acima. Para 
Klein, a narrativa é deveras mais complicada do que a habitual história, já contada inúmeras vezes, da invasão dos Estados Unidos pela "teoria francesa", que, dependendo de quem relata, poderia tanto ser a redenção de todos os males historiográficos ou, pelo contrário, a destruição dos pilares da disciplina. Chegamos ao segundo ponto crucial da análise de Klein: o papel da diferença cultural e, especialmente, da descolonização na emergência da linguistic turn, explorado nos dois capítulos seguintes. Seguindo um percurso pouco transitado por alguns analistas, como Gabrielle Spiegel (The past as text. Baltimore, 1997. p. 29-43) e Ethan Kleinberg (Haunting history: deconstruction and the spirit of revision. History and Theory, p. 113-143, Dec. 2007), o autor busca uma das origens, mas não a única, da virada linguística nos vínculos da antropologia geertziana com a etnolinguística norte-americana da primeira metade do século XX. Ao contrário da linguística europeia, preocupada em encontrar constâncias e uma gênese comum às línguas do Velho Mundo, a etnolinguística estadunidense lidou desde seu início com o choque cultural entre indígenas e europeus e euro-americanos, como demonstrariam os trabalhos pioneiros de Suzanne Langer e Edward Sapir (p. 69-71). O resultado foi uma apreciação da cultura como um fenômeno da linguagem e, por isso, relativa ao lugar daquele que fala, não existindo, portanto, posiçóes universais que pudessem arbitrar entre culturas diversas. Dessa forma, por exemplo, a própria ciência ocidental seria apenas um dos diversos discursos possíveis sobre a realidade, mas não o único. Com a conjugação entre "cultura" e "linguagem", deram-se, assim, as possibilidades semânticas para a emergência da antropologia geertziana e, por conseguinte, para uma das raízes da virada linguística nos Estados Unidos. Mesmo não desprezando em momento algum o papel de textos franceses e alemães para o surgimento da linguistic turn, Klein (p. 82-83) chega a duas importantes conclusões: em primeiro lugar, a de que os textos europeus tradicionalmente considerados os propulsores da virada linguística em terras norte-americanas são apenas uma parte de um corpus textual muito maior; em segundo lugar, a inferência de que o vocabulário da etnolinguística estadunidense moldou a tradução das "revoluçôes linguísticas do maio de 68 francês" (p. 83) no outro lado do Atlântico, que não pode ser devidamente entendida sem esse diálogo entre essas duas tradições.

No entanto, quando menos se espera, o fantasma de Hegel e sua "história universal" surgem novamente no horizonte. Para Klein, o pós-modernismo, ao menos em seu formato norte-americano, pode também ser entendido como uma refiguração do velho dictum hegeliano acerca dos "povos sem história”. Agora, contudo, não ter história era algo a ser celebrado e desejado pelos subalternos, como propóe Klein a partir da análise de uma série de autores, como James Clifford, Richard Rorty, Jean François Lyotard e, claro, Claude Lévi-Strauss. No que talvez seja uma das melhores análises do livro, Klein demonstra como, para os intelectuais acima mencionados, a história podia ser compreendida como um discurso colonizador e imperialista e imposto à for- 
ça aos povos conquistados pelos europeus. A manutenção dessa antinomia, com a reificação de velhos binarismos entre "mito" e "história", "metanarrativas" e "narrativas locais", "histórico" e "não histórico", é algo que assombra o "pós-modernismo" como seu "outro reacionário" (p. 101-102). Ao invés da celebração acrítica das narrativas subalternas, sejam elas quais forem, como resistência a uma todo-poderosa "história", é necessário ter em mente o constante processo de reinvenção cultural pelo qual passam as narrativas, que incluem tanto aquelas grandes narrativas herdeiras de Hegel quanto as histórias locais tomadas como oposição àqueles desígnios globais, para usar a expressão de Walter Mignolo (Local histories/global designs. Princeton, 2001). As posições que determinadas histórias ocupam social e culturalmente são sempre contingentes; nada garante que a história subalterna de hoje não se transformará na grande narrativa “opressora” de amanhã (p. 110-111). Nesse sentido, ao invés de imaginarmos a "história" como algo que os europeus inventaram e depois impuseram ao resto do globo a ferro, fogo e livros, seria melhor imaginarmos o mundo como contendo uma profusão de histórias e tradições narrativas em diálogo e conflito, já que só isso permitiria, na visão de Klein, um discurso histórico global realmente democrático e desprovido de essencialismos e antinomias de todo o tipo. Diante das forças homogenizadoras do capitalismo contemporâneo, que fazem tabula rasa das diferenças planetárias para nos transformar em felizes consumidores pertencentes a uma "aldeia global" amorfa e indistinta, realizando o velho sonho neoliberal do "fim da história", a exortação de Klein se faz, assim, essencial para a manutenção da história enquanto um discurso crítico, e não celebrador, do presente.

É esse potencial crítico que leva Klein a fazer, nos capítulos finais do livro, uma genealogia do conceito de "memória" em dois âmbitos diferentes e quase antagônicos, o do discurso histórico profissional e o do discurso da direita cristã que emergiu com força nos Estados Unidos dos anos 1970 e 1980. Para Klein, a emergência de "memória" como um conceito marcou uma mudança dramática nas práticas linguísticas das Humanidades contemporâneas, principalmente porque se tratou de um câmbio muito rápido e intenso. Em uma década, aproximadamente, as ciências humanas foram inundadas com o que pode ser corretamente chamado de uma "indústria de memória", com o surgimento de periódicos especializados (History and Memory e Memory Studies, por exemplo) e a publicação de um sem-número de livros sobre o tema (p. 113-114). No entanto, se a memory turn pode ser entendida como uma reação compreensível à virada linguística e seu antifundacionalismo, a ideia de "memória" acabou canibalizando outros conceitos, muitas vezes imprimindo uma confusão linguística e conceitual à história bastante condenável, ao menos sob o ponto de vista de Klein. "Memória" passou, assim, a ser considerada, dentre outras coisas, uma antítese subalterna à "história" imperialista; algo quase místico encarnado em objetos e corpos; um agente histórico em si mesmo; uma resposta aos grandes traumas da modernidade, especialmente o Holocausto; e, finalmente, uma 
forma de discurso pretensamente científico, emprestado à psicanálise, e com aspiraçóes curativas dificilmente concretizáveis (p. 116128). O que todos esses usos têm em comum é justamente a sacralização da memória como uma alternativa terapêutica à história, transparecendo inclusive em autores pouco dados a visões "místicas" da história, como Dominick LaCapra e Saul Friedlander. No final das contas, a ampla, e às vezes exagerada, utilização do conceito refletiria, nos Estados Unidos, ao menos, uma vontade de "reencantar nossa relação com o mundo e encher o passado com presença" (p. 137), especialmente diante da "ameaça" da "virada linguística" e da suposta falta de sentido do mundo pós-pós-moderno, para parafrasear Nancy Partner.

Tais usos não seriam tão perigosos em disciplinas que se pretendem críticas e seculares, se, por outro lado, no mundo extra-acadêmico eles não estivessem avalizando e legitimando a emergência de forças políticas antidemocráticas e antisseculares. Estamos aqui falando do surgimento da direita cristã a partir dos anos 1970 e sua consolidação como uma personagem política importante na década seguinte, quando Ronald Reagan, de forma muito hábil, reuniu a cruz (os fundamentalistas cristáos) e o dinheiro (os fundamentalistas neoliberais de Wall Street) debaixo da asa do Partido Republicano. Três fenômenos intelectuais caminharam de mãos dadas com esse fato: a utilização de um vocabulário memorialístico pelos conservadores cristãos, que entendiam o "abandono" do cristianismo pelos estadunidenses como o "trauma" maior da história do país e urgiam, assim, um retorno às raízes religiosas nacionais; o desenvolvimento de uma teologia da história que incentivava a releitura do passado norte-americano a partir de uma ótica fundamentalista, que entendia a história do país como a luta literal entre o Bem e o Mal, isto é, entre os seguidores de Jeová e as hostes satânicas que haviam sequestrado o país; e, finalmente, a formulação de uma ideologia política cristã que rejeitava os valores liberais e republicanos comumente associados com o sistema político norte-americano e que defendia o fim do secularismo como essencial para a reconstrução cristã da América. Desta forma, Klein (p. 159) identifica a "memory talk" predominante nos Estados Unidos contemporâneos, inclusive em alguns de seus usos acadêmicos supostamente críticos, como um sintoma da ressacralização da vida pública em seu país, com consequências mais amplas bastante preocupantes (e justificadas, diante do avanço tremendo da extrema direita cristã na última década — cujos efeitos, sabemos, já começam a ser sentidos no Brasil...). Uma das possíveis respostas a isso, para ele, é justamente o restabelecimento da história como uma disciplina crítica, secular e em constante interrogação dos conceitos e narrativas que a sustentam, na academia e fora dela, e, por isso, capaz de responder ao avanço dessas forças antidemocráticas.

No fim, a mensagem de From history to theory é relativamente simples, mas poderosa: a história, para ter algum poder efetivo de crítica sobre o presente, precisa necessariamente se historicizar constantemente e compreender as tradiçôes linguísticas e nar- 
rativas nas quais se insere, pois, sabemos, a disciplina não existe no vácuo. $\mathrm{O}$ que falamos e como falamos diz respeito tanto ao que herdamos do passado quanto aos diálogos que mantemos no presente. Por isso, o livro de Klein é uma leitura recomendada não só para aqueles que querem aprender sobre os controversos caminhos da história estadunidense no século XX, mas para todos que compreendem que, sem uma constante autorreflexão teórica e crítica maior, a disciplina está fadada a ser apenas algo feito por acadêmicos para acadêmicos, sem qualquer relevância pública maior. Aqui, concordo com Klein: tal coisa não é só indesejável, é perigosa.

${ }^{*}$ Doutor em história pela Universidade Federal do Rio Grande do Sul, professor adjunto da mesma universidade. Porto Alegre, RS, Brasil. E-mail: arthurlavila@gmail.com. 